\title{
Formação de Cobertura Vegetal e manejo de Plantas daninhas na Cultura da SoJa em Sistema Plantio Direto ${ }^{1}$
}

\author{
Straw Cover Formation and Weed Management in Soybean under No-Tillage System \\ NUNES, A.S..$^{2}$, TIMOSSI, P.C. ${ }^{3}$, PAVANI, M.C.MO.D. ${ }^{4}$ eCOSTA ALVES, A.P.L. ${ }^{5}$
}

\begin{abstract}
RESUMO - Objetivou-se com este trabalho avaliar a formação de cobertura vegetal por Brachiaria brizantha e $B$. decumbens, bem como as interações entre as coberturas vegetais, as dosagens do herbicida glifosato e a aplicação da mistura fluazifop-p-butil + fomesafen, no manejo das plantas daninhas e na produção da soja MG/BR 46 - Conquista em sistema plantio direto. Utilizou-se delineamento experimental de blocos ao acaso, num esquema de parcelas subsubdivididas, com quatro repetições. Testaram-se duas espécies de braquiária ( $B$. brizantha e $B$. decumbens), duas dosagens do herbicida glifosato $(1,44$ e 2,16 kg e.a. ha-1) e duas dosagens da mistura fluazifop-p-butil + fomesafen $\left(0\right.$ e $0,25+0,25 \mathrm{~kg}$ i.a. ha- $\left.{ }^{-1}\right)$. Foram realizadas avaliações de matéria seca das coberturas, eficácia do glifosato, rebrote das coberturas, altura das plantas de soja, número de vagens, altura de inserção da primeira vagem, acamamento, dificuldade de colheita, massa de 100 grãos e produtividade. Concluiu-se que $B$. decumbens e $B$. brizantha proporcionaram adequada cobertura do solo durante todo o ciclo da cultura, que a dosagem de 1,44 kg e.a. ha-1 de glifosato foi suficiente para o controle das duas espécies de braquiária e que a produtividade da cultura da soja não foi alterada significativamente pela palhada das duas espécies estudadas nem pela dosagem do glifosato, enquanto a aplicação de fluazifop-p-butil + fomesafen como controle complementar refletiu em maior produtividade e em menor dificuldade de colheita.
\end{abstract}

Palavras-chave: fluazifop-p-butil + fomesafen, glifosato, palhada, plantas daninhas.

\begin{abstract}
This work aimed to evaluate straw cover formation by Brachiaria brizantha and B. decumbens, and the interactions between straw cover, glyphosate rate and fluazifop-butyl-p + fomesafen application in weed management and soybean MG/BR 46-Conquista production under no-tillage. The experiment was arranged in a randomized block design in split-plot, with four repetitions. Two Brachiaria species (B. brizantha and B. decumbens), two glyphosate rates (1.44 and $2.16 \mathrm{~kg}$ i.a. $\left.\mathrm{ha}^{-1}\right)$ and two fluazifop-butyl-p + fomesafen rates $\left(0\right.$ and $0.25+0.25 \mathrm{~kg}^{\text {i.a }}$. ha $\left.\mathrm{h}^{-1}\right)$ were evaluated. Evaluations were carried out on straw cover dry matter, glyphosate effectiveness, hedge re-growth, soybean plant height, pod number, first pod height, lodging, harvest difficulty, mass of 100 seeds and yield. It was concluded that B. decumbens and B. brizantha provided adequate coverage of soil throughout the crop cycle; glyphosate rate of $1.44 \mathrm{~kg}$ i.a. ha $\mathrm{H}^{-1}$ was sufficient to control the two Brachiaria species; and soybean yield was not affected significantly by the straw of the two species, or by glyphosate rate, while fluazifop-butyl-p + fomesafen application as complementary control led to greater yield and less harvest difficulty.
\end{abstract}

Keywords: fluazifop-p-butyl + fomesafen, glyphosate, straw, weeds

Recebido para publicação em 6.10.2009 e na forma revisada em 12.11.2010.

2 Engo-Agrōo-, MSc., Aluno de Doutorado do Programa de Pós-Graduação em Agronomia, Universidade Federal da Grande Dourados -UFGD, Rua Hayel Bon Faker, Jd. Caramuru, 79806-000 Dourados-MS, <anisionunes@yahoo.com.br>; ${ }^{4}$ Professora, Dra., Universidade Federal de Goiás - UFG, campus de Jataí; ${ }^{5}$ Professor, Dr., Faculdade de Ciências Agrárias e Veterinárias FCAV/UNESP, Jaboticabal-SP.

Planta Daninha, Viçosa-MG, v. 28, n. 4, p. 727-733, 2010 


\section{INTRODUÇÃO}

O sistema plantio direto pode ser conceituado como um conjunto de processos tecnológicos destinados à exploração de sistemas agrícolas que contempla a diversificação de espécies via rotação e/ou consorciação de culturas, a mobilização do solo apenas na linha ou cova de semeadura e a manutenção permanente da cobertura do solo. Apesar da utilização dessa tecnologia em pelo menos metade da área agrícola do Brasil (FEBRAPDP, 2008), existem discussões pontuais que ainda necessitam de estudos, como a identificação de espécies que possam ser empregadas na formação e manutenção da cobertura vegetal, mesmo em condições tropicais, bem como suas interferências na cultura em sucessão.

As espécies do gênero Brachiaria destacam-se entre as alternativas para formação da palhada no sistema plantio direto por serem capazes de produzir palha em quantidade suficiente, com alta relação $\mathrm{C} / \mathrm{N}$ (característica das gramineas tropicais), sensibilidade ao manejo químico e alto grau de aproveitamento da umidade residual do solo (Timossi et al., 2006). Entretanto, estudos realizados por Souza et al. (2006) sobre os efeitos alelopáticos de $B$. decumbens no crescimento inicial de milho, arroz, trigo, soja, feijão, algodão e na dinâmica do nitrogênio no solo mostram que o crescimento dessas plantas foi reduzido com a adição de $B$. decumbens e que a incorporação da matéria seca da parte aérea dessa espécie reduziu significativamente os teores de nitrato no solo.

Outra questão importante a ser considerada nesse contexto é o processo de manejo químico dessas espécies antes da semeadura. Entre os herbicidas utilizados com essa finalidade, destaca-se o glifosato, um herbicida organofosfato (N-fosfonometil-glicina), não seletivo, sistêmico e que representa $60 \%$ do mercado mundial de herbicidas não seletivos. Seu mecanismo de ação baseia-se na interrupção da rota do ácido shiquímico, responsável pela produção dos aminoácidos aromáticos fenilalanina, tirosina e triptofano, essenciais para a sintese proteica e divisão celular em regiões meristemáticas da planta. Uma das vantagens desse herbicida é sua baixa toxicidade aos mamíferos e à vida aquática
(Amarante Júnior et al., 2002). A Embrapa (2007) recomenda o período de 30 dias entre o manejo de espécies do gênero Brachiaria e a semeadura da soja e uma dosagem que varia de 1,8 a 2,16 kg e.a. ha ${ }^{1}$ de glifosato.

Quando o manejo químico das coberturas vegetais é bem sucedido, com formação de camada de palha em quantidade e distribuição uniforme sobre o solo, a densidade populacional de plantas daninhas emergidas tende a ser menor. Assim, o uso de herbicidas em pósemergência da cultura pode ser recomendado para o controle pontual dessas plantas. Utilizada em cultivos de soja convencional para o controle complementar em pós-emergência da cultura, a mistura comercial de fluazifop-pbutil + fomesafen proporciona controle eficiente para a maioria das plantas daninhas mono e dicotiledôneas (Timossi \& Durigan, 2002).

A obtenção de bons resultados no sistema plantio direto está diretamente relacionada ao manejo adequado das culturas vegetais, combinado com um eficiente controle químico das plantas daninhas. Entretanto, muitas dúvidas sobre as interações entre coberturas vegetais e herbicidas no controle de plantas daninhas ainda precisam ser esclarecidas para que o agricultor possa usufruir de todos os benefícios do sistema (Correia et al., 2005).

O objetivo deste trabalho foi avaliar a formação de cobertura vegetal constituída por $B$. brizantha e $B$. decumbens, bem como as interações entre as coberturas vegetais, dosagens do herbicida glifosato e a aplicação da mistura fluazifop-p-butil + fomesafen no manejo das plantas daninhas e na produção da cultura da soja em sistema plantio direto.

\section{MATERIAL E MÉTODOS}

O experimento foi conduzido em área experimental pertencente à Faculdade de Ciências Agrárias e Veterinárias da Unesp, campus de Jaboticabal, na safra 2005/2006. As coberturas vegetais foram provenientes do segundo ano agrícola na área. No primeiro ano foi realizada a semeadura das espécies de braquiária, no início de março, na quantidade de $20 \mathrm{~kg} \mathrm{ha}^{-1}$ de sementes para cada espécie. Em seguida ocorreu o manejo das espécies e 
a semeadura da soja; após a colheita, a área ficou em pousio.

O experimento foi composto por oito tratamentos, constituídos por duas espécies de braquiária ( $B$. brizantha e $B$. decumbens), duas dosagens do herbicida glifosato para o manejo químico delas (1,44 e 2,16 $\mathrm{kg} \mathrm{ha}^{-1}$ de equivalente ácido) e duas dosagens da mistura fluazifopp-butil + fomesafen $\left(0\right.$ e $0,25+0,25 \mathrm{~kg} \mathrm{ha}^{-1} \mathrm{de}$ ingrediente ativo). O delineamento experimental utilizado foi o de blocos ao acaso, num esquema de parcelas subsubdivididas, com quatro repetições. As parcelas possuíam dimensões de $50 \times 7 \mathrm{~m}$ e representavam as espécies de braquiária; nas subparcelas, com dimensões de $25 \times 7 \mathrm{~m}$, testaram-se as dosagens do herbicida de manejo; e nas subsubparcelas, de $12,5 \times 7 \mathrm{~m}$, as dosagens do herbicida de controle complementar. As unidades experimentais possuiam sete linhas de soja.

O herbicida glifosato foi aplicado com pulverizador costal pressurizado por $\mathrm{CO}_{2}$ à pressão constante de $28 \mathrm{lbf} \mathrm{pol}^{-2}$ e munido de uma barra com quatro bicos de jato plano ("leque") XR 11002, espaçados de 0,5 m, com consumo de calda equivalente a $200 \mathrm{~L} \mathrm{ha}^{-1}$. No dia da aplicação do glifosato para controle das coberturas, as plantas de braquiária encontravam-se com cerca de 0,65 m de altura, vigorosas e constatava-se apenas a presença das espécies em estudo.

O cultivar de soja MG/BR 46-Conquista é recomendado para os Estados de MG, SP, MT, GO e DF; possui hábito de crescimento determinado, ciclo médio, $0,82 \mathrm{~m}$ de altura média de plantas e $0,15 \mathrm{~m}$ de altura média de inserção da primeira vagem (COMIGO, 2005). A semeadura da soja foi realizada 27 dias após o manejo químico das coberturas. As sementes foram tratadas com thiram e com Bradyrizobium japonicum. A semeadura foi realizada mecanicamente, com espaçamento entre linhas de $0,45 \mathrm{~m}$ e uma população de 350.000 plantas ha ${ }^{-1}$. A adubação de semeadura foi realizada com $60 \mathrm{~kg} \mathrm{ha}^{-1}$ de $\mathrm{P}_{2} \mathrm{O}_{5}$ e $60 \mathrm{~kg} \mathrm{ha}^{-1}$ de $\mathrm{K}_{2} \mathrm{O}$. Houve necessidade de duas pulverizações com o fungicida tebuconazole para o controle da ferrugem-asiática (Phakospora pachyrhizi), realizadas nos estádios $R_{2}$ e $R_{5}$ da soja.
A aplicação da mistura fluazifop-p-butil + fomesafen foi realizada 30 dias após a semeadura, quando as plantas de soja se encontravam no estádio $\mathrm{V}_{5}$, com um pulverizador costal pressurizado por $\mathrm{CO}_{2}$ à pressão constante de 28 lbf pol-2, uma barra com quatro bicos de jato plano ("leque") XR 11002, espaçados de $0,5 \mathrm{~m}$, e um consumo de calda equivalente a $200 \mathrm{~L} \mathrm{ha}^{-1}$. O controle químico de pragas não foi necessário.

Foram realizadas quatro amostragens da matéria seca inicial por cobertura vegetal, aleatoriamente, na área experimental, cinco dias após o manejo delas, utilizando-se um quadrado de $1 \mathrm{~m}^{2}(1 \times 1 \mathrm{~m})$. O material vegetativo foi cortado rente ao solo, colocado em sacos de papel e seco em estufa de circulação forçada de ar, à temperatura de $60{ }^{\circ} \mathrm{C}$, durante 72 horas. A avaliação da matéria seca remanescente no final do ciclo foi realizada na colheita da cultura, que ocorreu 135 dias após a semeadura (DAS), seguindo a mesma metodologia. A taxa de decomposição foi calculada pela diferença entre a massa inicial e a final, em função do período decorrido.

As avaliações de eficácia de controle pelo herbicida glifosato foram realizadas aos $10 \mathrm{e}$ aos 20 dias após aplicação. Notas visuais de controle foram atribuídas numa escala de porcentagem de 0 a 100, em que 0 representa nenhum efeito do herbicida e 100 o controle total das plantas daninhas. O rebrote das espécies de braquiária foi avaliado aos 10, 20 e 30 dias após a semeadura da soja, por meio de notas visuais, numa escala de porcentagem em que 0 representa nenhum rebrote e 100 a cobertura total da subparcela pelos rebrotes. A avaliação de eficácia da mistura fluazifop-p-butil + fomesafen na comunidade infestante foi realizada por meio de observações visuais.

Antes da realização da colheita da soja, nas áreas úteis de cada subsubparcela realizaramse as avaliações de altura média das plantas de soja e de porcentagem de acamamento, considerando-se acamadas as plantas que apresentassem inclinação superior a $45^{\circ} \mathrm{em}$ relação à vertical. O nível de dificuldade de colheita também foi estimado visualmente e inferido com base na porcentagem de cobertura por plantas daninhas na área útil das subsubparcelas do experimento.

Planta Daninha, Viçosa-MG, v. 28, n. 4, p. 727-733, 2010 
As plantas presentes nos cinco metros da linha central de cada subsubparcela foram colhidas manualmente, sendo posteriormente trilhadas. Para expressão de produtividade e massa seca de 100 grãos, a umidade dos grãos foi corrigida para $13 \%$. Com as plantas colhidas na área útil de cada unidade experimental, foram determinadas algumas características relacionadas à produção, como: altura de inserção da primeira vagem (centímetros), número de vagens por planta e rendimento de grãos. Esses dados foram obtidos de 10 plantas seguidas, tomadas ao acaso, do total colhido na subsubparcela. As massas de 100 grãos foram avaliadas em cada subsubparcela colhida, com base nas recomendações das Regras para Análise de Sementes (Brasil, 1992).

Os dados obtidos nas diferentes avaliações foram submetidos à análise de variância pelo teste F; para comparação das médias, utilizouse o teste de Tukey a $5 \%$ de probabilidade.

\section{RESULTADOS E DISCUSSÃO}

A quantidade de palha sobre o solo e a uniformidade de sua distribuição podem servir de referência para uma avaliação preliminar sobre as condições em que o sistema plantio direto está se desenvolvendo. No momento da semeadura, as quantidades de palha de $B$. brizantha e $B$. decumbens encontradas foram, respectivamente, de 8,7 e $11,2 \mathrm{t} \mathrm{ha}^{-1}$, não diferindo estatisticamente entre si (Tabela 1). No ano agrícola anterior, em que as braquiárias foram semeadas, Timossi et al. (2006) encontraram, na mesma área, 14,6 t ha ${ }^{-1}$ de massa vegetal seca para $B$. brizantha e 7,4 t ha $^{-1}$ para $B$. decumbens. Essa inversão da espécie mais produtiva que ocorreu de um ano para o outro se deve à maior capacidade de reinfestação de $B$. decumbens. Observou-se um estiolamento das plântulas de soja, principalmente nas parcelas com $B$. brizantha, devido à menor acomodação da camada de palha na superficie do solo nas parcelas com palha de $B$. brizantha. A emergência das plântulas de soja ocorreu praticamente na ausência de plantas daninhas.

Nunes et al. (2006) avaliaram a produção de palha por diferentes plantas de cobertura e quantificaram $11,1 \mathrm{t} \mathrm{ha}^{-1}$ de matéria seca para $B$. decumbens e 6,2 $\mathrm{t} \mathrm{ha}^{-1}$ para $B$. brizantha.
Silva et al. (2005) encontraram 13,3 $\mathrm{t} \mathrm{ha}^{-1}$ de matéria seca para $B$. brizantha, valor superior ao verificado neste experimento, devido principalmente às diferenças edafoclimáticas e de manejo. Segundo resultados obtidos por Alvarenga et al. (2001), a quantidade de $6,0 \mathrm{t} \mathrm{ha}^{-1}$ de matéria seca da cobertura vegetal é suficiente para cobrir totalmente o solo.

Na colheita (135 DAS), as parcelas com $B$. brizantha apresentaram a quantidade de $7,2 \mathrm{t} \mathrm{ha}^{-1}$ de matéria seca, superior à encontrada nas parcelas com $B$. decumbens, que foi de 5,7 t ha ${ }^{-1}$ (Tabela 1). A taxa de decomposição dos resíduos de $B$. decumbens foi três vezes maior que a dos de $B$. brizantha, provavelmente devido à menor relação $\mathrm{C} / \mathrm{N}$ e ao menor teor de lignina, celulose e hemicelulose em $B$. decumbens. Entretanto, as duas espécies de braquiária apresentaram, na época da colheita da soja, uma quantidade de matéria seca próxima a $6,0 \mathrm{t} \mathrm{ha}^{-1}$, deixando evidente que a cobertura do solo foi adequada durante todo o ciclo da cultura.

O controle com glifosato foi satisfatório nas duas espécies de braquiária estudadas. Entretanto, o controle de $B$. decumbens foi melhor que o de $B$. brizantha tanto aos 10 como aos 20 dias após a aplicação do herbicida (Tabela 2). Não houve diferença estatística entre as dosagens de glifosato testadas, porém, aos 10, 20 e 30 dias após a semeadura, observou-se rebrote das braquiárias; os valores encontrados em $B$. brizantha foram superiores aos observados em $B$. decumbens, resultado esse diretamente correlacionado com a eficiência do controle (Tabela 2). Pereira (1996) também concluiu que a dosagem de

Tabela 1 - Matéria seca das espécies de Brachiaria aos 27 e 172 dias após o manejo com glifosato, com respectiva taxa de decomposição. Jaboticabal-SP, 2005-06

\begin{tabular}{|l|c|c|c|}
\hline \multicolumn{1}{|c|}{ Espécie } & $\begin{array}{c}\text { Massa inicial } \\
\left(\mathrm{t} \mathrm{ha}^{-1}\right)\end{array}$ & $\begin{array}{c}\text { Massa final } \\
\left(\mathrm{t} \mathrm{ha}^{-1}\right)\end{array}$ & $\begin{array}{c}\text { Taxa de } \\
\text { decomposição } \\
\left(\mathrm{g} \mathrm{m}^{-2} \mathrm{dia}^{-1}\right)\end{array}$ \\
\hline B. brizantha & 8,7 & $7,2 \mathrm{a}$ & 1,0 \\
\hline B. decumbens & 11,2 & $5,7 \mathrm{~b}$ & 3,8 \\
\hline F & $2,1^{\mathrm{ns}}$ & $7,4^{*}$ & - \\
\hline $\mathrm{CV}(\%)$ & 17,4 & 10,1 & - \\
\hline
\end{tabular}

${ }^{\text {ns }}$ Não significativo. * Significativo a $5 \%$ de probabilidade. Médias seguidas por letras diferentes, na mesma coluna, diferem entre si pelo teste de Tukey a $5 \%$ de probabilidade. 
Tabela 2 - Controle (\%) e rebrote (\%) das espécies de Brachiaria pelo glifosato, avaliados em diferentes épocas, e número de vagens por planta de soja. Jaboticabal-SP, 2005-06

\begin{tabular}{|c|c|c|c|c|c|c|}
\hline & $\begin{array}{c}\text { Controle } 10 \\
\text { DAA }\end{array}$ & $\begin{array}{c}\text { Controle } 20 \\
\text { DAA }\end{array}$ & $\begin{array}{l}\text { Rebrote } 10 \\
\text { DAS }\end{array}$ & $\begin{array}{c}\text { Rebrote } 20 \\
\text { DAS }\end{array}$ & $\begin{array}{c}\text { Rebrote } 30 \\
\text { DAS }\end{array}$ & $\begin{array}{l}\text { Número de } \\
\text { vagens }\end{array}$ \\
\hline F Brachiaria & $9,6^{* *}$ & $22,8 * *$ & $52,9 * *$ & $13,8 * *$ & $25,3 * *$ & $0,4^{\mathrm{ns}}$ \\
\hline F glifosato & $2,8^{\mathrm{ns}}$ & $3,7^{\mathrm{ns}}$ & $0,5^{\mathrm{ns}}$ & $0,8^{\mathrm{ns}}$ & $0,4^{\mathrm{ns}}$ & $2,5^{\mathrm{ns}}$ \\
\hline F fluaz + fom & - & - & - & - & $0,2^{\mathrm{ns}}$ & $0,1^{\mathrm{ns}}$ \\
\hline F Blocos & $0,5^{\mathrm{ns}}$ & $3,4^{\mathrm{ns}}$ & $2,7^{\mathrm{ns}}$ & $0,9^{\mathrm{ns}}$ & $0,7^{\mathrm{ns}}$ & $2,9^{\mathrm{ns}}$ \\
\hline \multicolumn{7}{|c|}{ Espécie de Brachiaria } \\
\hline B. brizantha & $80,0 \mathrm{~b}$ & $87,5 \mathrm{~b}$ & $6,7 \mathrm{a}$ & $8,6 \mathrm{a}$ & $4,4 \mathrm{a}$ & 77,8 \\
\hline B. decumbens & $94,4 \mathrm{a}$ & $96,5 \mathrm{a}$ & $1,5 \mathrm{~b}$ & $3,0 \mathrm{~b}$ & $1,0 \mathrm{~b}$ & 80,6 \\
\hline \multicolumn{7}{|c|}{ Dosagem de glifosato (kg e.a. $\left.\mathrm{ha}^{-1}\right)$} \\
\hline 1,44 & 85,4 & 89,4 & 3,9 & 5,1 & 2,5 & 75,4 \\
\hline 2,16 & 89,4 & 94,6 & 4,4 & 6,5 & 2,9 & 82,9 \\
\hline \multicolumn{7}{|c|}{ Dosagem de fluazifop-p-butil + fomesafen (kg i.a. ha $\left.{ }^{-1}\right)$} \\
\hline $0,25+0,25$ & - & - & - & - & 2,6 & 79,6 \\
\hline 0 & - & - & - & - & 2,9 & 78,8 \\
\hline $\mathrm{CV}(\%)$ & 6,0 & 4,1 & 34,9 & 22,1 & 21,0 & 16,9 \\
\hline
\end{tabular}

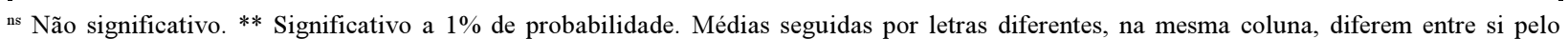
teste de Tukey a $5 \%$ de probabilidade. DAA = dias após a aplicação e DAS = dias após a semeadura da soja.

$1,44 \mathrm{~kg}$ e.a. ha- $\mathrm{h}^{-1}$ foi eficaz no controle de B. decumbens, com $16 \mathrm{t} \mathrm{ha}^{-1}$ de matéria seca. Já Timossi et al. (2006), estudando o uso de glifosato no manejo químico de espécies de Brachiaria, observaram que o controle de $B$. decumbens e $B$. brizantha foi satisfatório a partir da dosagem de $2,16 \mathrm{~kg}$ e.a. ha ${ }^{-1}$ de glifosato, porém não foi capaz de evitar totalmente a probabilidade de ocorrência de rebrotes. Essas diferenças de eficácia nas dosagens de glifosato podem ser explicadas pela diferença de idade das plantas no momento do manejo.

O manejo da cultura favoreceu a seleção de Alternanthera tenella, independentemente da espécie de Brachiaria. Por ocasião da aplicação da mistura fluazifop-p-butil + fomesafen, verificou-se que a comunidade infestante foi composta principalmente por Cyperus rotundus, A. tenella e Amaranthus spp. As palhadas de $B$. decumbens e de $B$. brizantha não apresentaram efeito inibitório sobre as plantas de Amaranthus spp. e de A. tenella. O controle de A. tenella pela mistura fluazifop-p-butil + fomesafen foi satisfatório já aos 10 DAA, não se observando diferença em relação às espécies de braquiária e às dosagens de glifosato empregadas.
Os tratamentos testados não alteraram significativamente o número de vagens por planta, a massa de 100 grãos, a altura de plantas e a altura de inserção da primeira vagem, o que indica que, mesmo na presença da comunidade infestante e de rebrotes das espécies de Brachiaria, a cultura foi capaz de competir pelos recursos do meio, caracterizando assim a capacidade competitiva do cultivar utilizado (Tabelas 2 e 3). As subparcelas tratadas com a mistura fluazifop-p-butil + fomesafen como controle complementar apresentaram maior produtividade, menor acamamento e menor dificuldade de colheita (Tabela 3), devido à ausência de plantas daninhas no momento da colheita.

Entre as plantas daninhas presentes no momento da colheita nas subsubparcelas sem aplicação da mistura fluazifop-p-butil + fomesafen, observou-se maior infestação de B. decumbens, A. tenella, Commelina benghalensis e Amaranthus spp. nas parcelas com cobertura vegetal de $B$. decumbens e de A. tenella, $B$. brizantha e Amaranthus spp. nas parcelas com cobertura vegetal de $B$. brizantha. Nepomuceno et al. (2007), estudando os períodos de interferência das plantas daninhas 
Tabela 3 - Altura das plantas de soja (cm), altura de inserção da primeira vagem $(\mathrm{cm})$, produtividade $\left(\mathrm{kg} \mathrm{ha}^{-1}\right)$, massa de 100 grãos $(\mathrm{g})$, acamamento (\%) e dificuldade de colheita (\%). Jaboticabal-SP, 2005-06

\begin{tabular}{|c|c|c|c|c|c|c|}
\hline & $\begin{array}{l}\text { Altura de } \\
\text { plantas }\end{array}$ & $\begin{array}{l}\text { Inserção } 1^{\mathrm{a}} \\
\text { vagem }\end{array}$ & Produtividade & $\begin{array}{c}\text { Massa } 100 \\
\text { grãos }\end{array}$ & Acamamento & $\begin{array}{l}\text { Dificuldade de } \\
\text { colheita }\end{array}$ \\
\hline F Brachiaria & $0,1^{\mathrm{ns}}$ & $1,2^{\mathrm{ns}}$ & $3,6^{\mathrm{ns}}$ & $0,2^{\mathrm{ns}}$ & $0,8^{\mathrm{ns}}$ & $0,3^{\mathrm{ns}}$ \\
\hline F glifosato & $0,1^{\mathrm{ns}}$ & $3,4^{\text {ns }}$ & $0,2^{\mathrm{ns}}$ & $0,7^{\mathrm{ns}}$ & $0,4^{\mathrm{ns}}$ & $0,3^{\mathrm{ns}}$ \\
\hline F fluaz+fom & $0,2^{\mathrm{ns}}$ & $0,4^{\mathrm{ns}}$ & $16,5 * *$ & $0,1^{\mathrm{ns}}$ & $13,2 * *$ & $354,9 * *$ \\
\hline F Blocos & $3,0^{\mathrm{ns}}$ & $3,9^{\text {ns }}$ & $1,8^{\mathrm{ns}}$ & $1,4^{\mathrm{ns}}$ & $1,2^{\mathrm{ns}}$ & $2,3^{\mathrm{ns}}$ \\
\hline \multicolumn{7}{|c|}{ Espécie de Brachiaria } \\
\hline B. brizantha & 82,0 & 21,9 & 3117,9 & 15,4 & 4,3 & 37,2 \\
\hline B. decumbens & 81,3 & 20,9 & 3483,8 & 15,6 & 3,4 & 35,0 \\
\hline \multicolumn{7}{|c|}{ Dosagem de glifosato $\left(\mathrm{kg}\right.$ e.a. $\left.\mathrm{ha}^{-1}\right)$} \\
\hline 1,44 & 81,3 & 22,6 & 3254,5 & 15,4 & 4,2 & 37,2 \\
\hline 2,16 & 81,9 & 20,2 & 3347,2 & 15,7 & 3,5 & 35,0 \\
\hline \multicolumn{7}{|c|}{ Dosagem de fluazifop-p-butil + fomesafen $\left(\mathrm{kg}\right.$ i.a. $\left.\mathrm{ha}^{-1}\right)$} \\
\hline $0,25+0,25$ & 81,1 & 21,7 & $3693,2 \mathrm{a}$ & 15,5 & $1,9 \mathrm{~b}$ & $0,0 \mathrm{~b}$ \\
\hline 0 & 82,1 & 21,1 & $2908,5 \mathrm{~b}$ & 15,5 & $5,7 \mathrm{a}$ & $72,2 \mathrm{a}$ \\
\hline $\mathrm{CV}(\%)$ & 8,4 & 11,4 & 16,5 & 7,3 & 17,2 & 10,0 \\
\hline
\end{tabular}

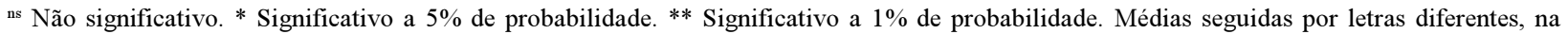
mesma coluna, diferem entre si pelo teste de Tukey a $5 \%$ de probabilidade.

A. tenella, Cenchrus echinatus e Bidens pilosa na cultura da soja, concluíram que a interferência dessas plantas durante todo o ciclo da cultura reduziu, em média, $46 \%$ a produtividade de grãos da soja e que não houve efeito das plantas daninhas na altura das plantas, na altura de inserção da primeira vagem e no número de vagens por planta. Nas subsubparcelas onde não foi aplicado o herbicida de controle complementar, a alta infestação de plantas daninhas e, principalmente, o rebrote das plantas de braquiária inviabilizam a colheita mecanizada (Tabela 3 ).

Com base nos resultados, pode-se concluir que: $B$. decumbens e $B$. brizantha proporcionaram adequada cobertura do solo durante todo o ciclo da cultura; a dosagem de $1,44 \mathrm{~kg}$ e.a. ha ${ }^{-1}$ de glifosato foi suficiente para o controle das duas espécies de braquiária testadas; e a produtividade da cultura da soja não foi alterada significativamente pela palhada das espécies estudadas, nem pela dosagem do herbicida glifosato utilizada no manejo destas, enquanto a aplicação da mistura fluazifop-p-butil + fomesafen como controle complementar refletiu em maior produtividade e em menor dificuldade de colheita.

\section{LITERATURA CITADA}

ALVARENGA, R. C. et al. Plantas de cobertura de solo para sistema de plantio direto. Inf. Agropec., v. 22, n. 1, p. 25-36, 2001 .

AMARANTE JUNIOR, O. P. et al. Glifosato: propriedades, toxicidade, usos e legislação. Química Nova, v. 25, n. 4, p. 589-593, 2002.

BRASIL. Ministério da Agricultura e da Reforma Agrária. Regras para análise de sementes. Brasília: SNDA/DNDV/ CLAV, 1992. p. 58-120.

COOPERATIVA MISTA DOS PRODUTORES RURAIS DO SUDOESTE GOIANO - COMIGO. Variedades de Soja. <www.comigo.com.br/arquivos/variedades2005.doc>. Acesso em: 5 nov. 2007)

CORREIA, N. M.; SOUZA, I. F.; KLINK, U. P. Palha de sorgo associada ao herbicida imazamox no controle de plantas daninhas na cultura da soja em sucessão. Planta Daninha, v. 23 , n. 3 , p. $483-489,2005$.

EMPRESA BRASILEIRA DE PESQUISA AGROPECUÁRIA - EMBRAPA. Controle de plantas daninhas, tecnologias de produção de soja. Londrina: 2007. p. 123-145. 
FEDERAÇÃO BRASILEIRA DE PLANTIO DIRETO NA PALHA - FEBRAPDP. Evolução da área de plantio direto no Brasil. Disponível: < http://www.febrapdp.org.br/port/ plantiodireto.html $>$ Acesso em: 10 maio 2008)

NEPOMUCENO, $M$. et al. Períodos de interferência das plantas daninhas na cultura da soja nos sistemas de semeadura direta e convencional. Planta Daninha, v. 25, n. 1, p. 43-50, 2007.

NUNES, U. R. et al. Produção de palhada de plantas de cobertura e rendimento do feijão em plantio direto. Pesq. Agropec. Bras., v.41, n. 6, p. 943-948, 2006.

PEREIRA, F. A. R. Determinação da dose eficiente de dessecantes sistêmicos no manejo de Brachiaria decumbens em plantio direto da soja, na região dos cerrados. In: SEMINÁRIO: ZAPP - O DESAFIO DO NOVO, 1995, São Paulo. Trabalhos apresentados... São Paulo: Zeneca Agrícola, 1996. p. 95-96.
SILVA, A. C. et al. Análise de crescimento de Brachiaria brizantha submetida a doses reduzidas de fluazifop-p-butil. Planta Daninha, v. 23, n. 1, p. 85-91, 2005.

SOUZA, L. S. et al. Efeito alelopático de capim-braquiária (Brachiaria decumbens) sobre o crescimento inicial de sete espécies de plantas cultivadas. Planta Daninha, v. 24, n. 4, p. 657-668, 2006.

TIMOSSI, P. C.; DURIGAN, J. C. Doses reduzidas de fluazifop-p-butil + fomesafen no controle de plantas daninhas na cultura da soja. Planta Daninha, v. 20, n. 3, p. 439-447, 2002 .

TIMOSSI, P. C.; DURIGAN, J. C.; LEITE, G. J. Eficácia de glyphosate em plantas de cobertura. Planta Daninha, v. 24, n. 3 , p. $475-480,2006$. 